\title{
Desiccant effect of starch in polylactic acid composites
}

\author{
J. Móczó ${ }^{1,2}$, D. Kun ${ }^{1,2}$, E. Fekete ${ }^{1,2^{*}}$ \\ ${ }^{1}$ Institute of Materials and Environmental Chemistry, Research Centre for Natural Sciences, Hungarian Academy \\ of Sciences, H-1117 Budapest, Magyar tudósok körútja 2., Hungary \\ ${ }^{2}$ Laboratory of Plastics and Rubber Technology, Department of Physical Chemistry and Materials Science, Budapest \\ University of Technology and Economics, H-1111 Budapest, Müegyetem rkp. 3., Hungary
}

Received 23 March 2018; accepted in revised form 11 June 2018

\begin{abstract}
Polylactic acid (PLA)/starch and PLA/starch-glycerol composites with different glycerol contents were prepared in a wide composition range, in order to study their applicability as packaging materials for dry products. Water uptake was determined at a temperature of $23^{\circ} \mathrm{C}$ and different relative humidities. Structure and mechanical properties were also investigated. PLA/ unplasticized starch composites could absorb a considerable amount of water. As a result, they may be adequate as a biodegradable inner container in dry packaging. The absorption capacity of the composites increased significantly with increasing starch content and relative humidity, respectively. Unplasticized starch exhibited not only a desiccant but also a reinforcing effect in PLA, thus both stiffness and strength increased with increasing starch loading. The influence of glycerol content on the water uptake was difficult to reveal due to the migration of glycerol from the bulk to the surface. Furthermore, glycerol weakened the PLA/starch adhesion and softened starch particles.
\end{abstract}

Keywords: biopolimers, biocomposites, thermoplastic starch, desiccant, polylactic acid

\section{Introduction}

Plastic packaging materials play an important role in the economy and our everyday life. Recently the increasing demands of consumers have resulted in new packaging systems, including functional and smart packaging materials [1-5]. Regulating the humidity of packaged wares is necessary in several areas: controlling moisture-content is important in food packaging $[6,7]$, while maintaining dry conditions is usually a requirement of packaging for pharmaceuticals [8-10] and electronic devices [11]. Humidity of the ambient atmosphere must be captured in the latter case, which is carried out through the adsorption or absorption of water by a desiccant. Desiccants can be added to the packaged ware in a semipermeable sachet or incorporated into the packaging material. Besides the usually used desiccants (silica gels, zeolites etc.) [12-18], intensive research is carried out to develop new desiccants, including hybrid (adsorbent/absorbent) materials, [12, 19, 20] natural polymers (starch, cellulose derivatives) [21, 22], and superabsorbent gels (acrylates, cellulose compounds) [23-26].

Several patents [27-29] give a solution for the production of containers made of desiccant polymer composites. Such containers can be applied for the packaging of drugs, electrical devices or dry foods to maintain moisture-free conditions. Polyolefins are commonly used as packaging materials, and they also can be filled with desiccants (for example with zeolite) resulting in desiccant polymer composites. The drawbacks of these materials are the slow diffusion of water in them and the fact that they are petroleum-based.

Recently a growing interest has been shown in the application of biopolymers as packaging materials 
in order to reduce the environmental pollution caused by plastic waste, and to achieve sustainable development. PLA is a promising option since it is environmentally friendly and suitable for a number of packaging applications, especially in food packaging. Increasing application area of PLA could be achieved by adding desiccants to pure PLA.

Starch is a natural desiccant which is readily available, cheap and biodegradable. The application of starch or starch derivatives as desiccants is not new in the industry: corn starch, corn grits, enzyme modified corn grits and other starch based materials have already been widely used as natural desiccants [3034]. These materials were found to be efficient and stable desiccants. Starch was also shown to selectively absorb water from ethanol/water vapor in fixed bed absorption systems [30, 35]. Furthermore, mixing PLA with other biodegradable polymers like starch, cellulose or thermoplastic starch (TPS) might result in cost reduction.

Because of the large water uptake and the considerable diffusion rate of water in PLA, PLA/starch or PLA/TPS composites can be suitable materials for containers maintaining dry conditions. Furthermore, former results [36-38] proved that the addition of starch or even glycerol containing starch (TPS) increases the biodegradability of PLA. One of the reasons of the increased biodegradability is the significant water absorption of the carbohydrate and glycerol. For this reason, some research groups investigated the hydrolytic aging of PLA at different relative humidities, and they found that the weight decrease of PLA samples at common relative humidity was negligible after some months [39]. In addition, it was also shown that the hydrolytic degradation is much slower than the diffusion of water in the polymer [40]. As a consequence, PLA/starch composites can be applied as a biodegradable inner container in drug or dry food packaging, and when their time is over, they can be biodegraded more easily than neat PLA.

In spite of the large number of publications dealing with PLA/starch and PLA/TPS composites and blends [41-45], only a few studies are available on the sorption (water absorption) properties of these materials $[36,46]$. The water absorption of starch can be improved by the addition of low molecular weight, hygroscopic polyols, like glycerol, xylitol, sorbitol, etc. The proper selection of these components is very important as the equilibrium water uptake decreases with the increasing molecular weight of the plasticizer [47]. Furthermore, the addition of plasticizers might lead to the formation of thermoplastic starch and the development of PLA/TPS blends [48]. According to our previous results, in TPS strong interactions (hydrogen bonds) develop between glycerol and starch decreasing the hygroscopy of glycerol [49]. Accordingly, a simple dry blending of starch and glycerol without heat and shear forces seems to be more beneficial if enhanced water absorption capacity is required.

The aim of the research was to prepare PLA/starch and PLA/starch-glycerol composites in a wide composition range, with different glycerol content, and to determine the water sorption of these composites at different value of relative humidity, as well as to characterize their mechanical and morphological properties. The effect of both starch and glycerol content on the composite properties was also investigated.

\section{Experimental}

\subsection{Materials}

PLA used was obtained from NatureWorks (USA, Ingeo $4032 \mathrm{D}, M_{\mathrm{n}}=88500 \mathrm{~g} \cdot \mathrm{mol}^{-1}$ and $M_{\mathrm{w}} / M_{\mathrm{n}}=$ $1.8)$. The polymer ( $<2 \% \mathrm{D}$ isomer) has a density of $1.24 \mathrm{~g} / \mathrm{cm}^{3}$, while its melt flow index (MFI) is $3.9 \mathrm{~g} / 10 \mathrm{~min}$ at $190^{\circ} \mathrm{C}$ and $2.16 \mathrm{~kg}$ load. Corn starch (S0) was supplied by Hungrana Ltd., Hungary, its water content was $12 \mathrm{wt} \%$. Glycerol with $0.5 \mathrm{wt} \%$ water content was obtained from Molar Chemicals Ltd., Hungary, and it was used without further purification or drying. Starch powders containing 12, 24, 36 and $47 \mathrm{wt} \%$ glycerol (S12, S24, S36 and S47, respectively) were prepared and used in the experiments. The composition of the PLA/starch composites changed from 0 to 0.5 volume fraction in 0.1 volume fraction steps.

\subsection{Sample preparation}

Corn starch and PLA were dried before composite preparation. Starch was dried at atmospheric pressure and $104^{\circ} \mathrm{C}$ for 24 hours, while PLA in a vacuum oven at $110^{\circ} \mathrm{C}$ for 4 hours. Starch/glycerol powders (S12, S24, S36, S47) were prepared by dryblending in a Henschel FM/A10 high speed mixer at $2000 \mathrm{rpm}$. PLA and starch (or starch/glycerol powders) were homogenized in an internal mixer (Brabender W 50 EHT) at $190^{\circ} \mathrm{C}$ and $50 \mathrm{rpm}$ for $12 \mathrm{~min}$. The homogenized material was compression molded 
into $1 \mathrm{~mm}$-thick plates for further testing, at $2.5 \mathrm{MPa}$ and $190^{\circ} \mathrm{C}$ using a Fontijne SRA 100 machine.

\subsection{Characterization}

The water absorption of neat PLA, S0, S24 and S47 powders, as well as PLA composites was determined by measuring the weights of $20 \times 20 \times 1 \mathrm{~mm}$ specimens as a function of time in an atmosphere of 50 and $100 \%$ relative humidity $(R H) .50 \% R H$ was maintained above a saturated solution of $\mathrm{Mg}\left(\mathrm{NO}_{3}\right)_{2}$. The initial and overall rates, as well as the final (equilibrium) amount of water uptake of the powders and composites were calculated from the absorption curves. The different starch powders were characterized by using a Horiba LA-950 A2 laser diffraction particle size distribution analyzer. Mechanical properties of all PLA/starch (S0, S12, S24, S36, S47) composites were determined by tensile testing using an Instron 5566 universal testing machine. Tensile modulus was measured at $0.5 \mathrm{~mm} / \mathrm{min}$, while properties at larger deformations (tensile strength, elongation-at-break) at $5 \mathrm{~mm} / \mathrm{min}$ cross-head speed. The glass transition temperature of the phases and other thermal transitions appearing in the composites were determined by dynamic mechanical analysis (DMA) using a Perkin Elmer Pyris Diamond DMA apparatus in tensile mode with constant amplitude $(10 \mu \mathrm{m})$ and frequency $(1 \mathrm{~Hz})$ in the temperature range between -80 and $100^{\circ} \mathrm{C}$. Heating rate was $2{ }^{\circ} \mathrm{C} / \mathrm{min}$, while the size of the specimens was $50 \times 5 \times 1 \mathrm{~mm}$. Samples were investigated before and after the water absorption test. In order to eliminate the effect of water on the glass transition temperature of TPS,

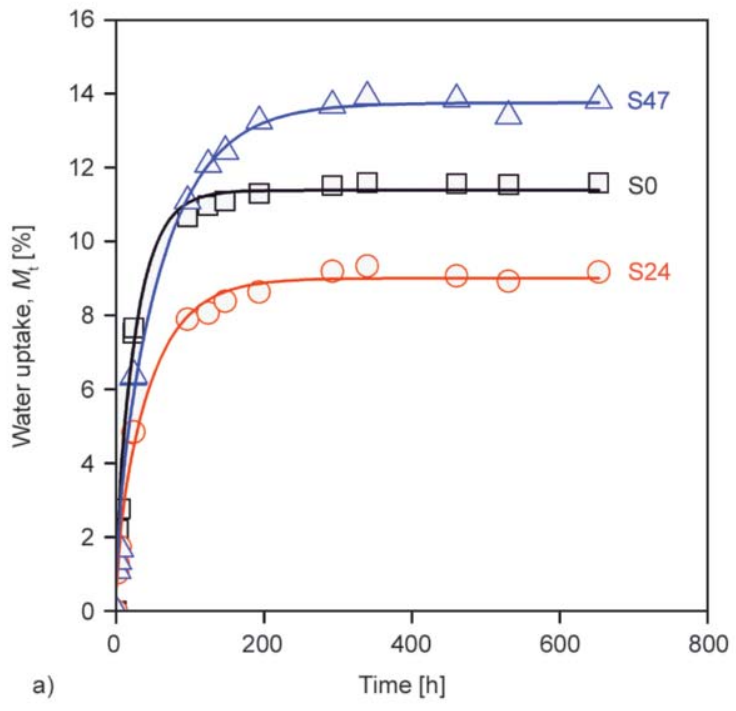

samples were dried in desiccator at $0 \% R H$ before the DMA measurements.

The structure of the composites was analyzed by scanning electron microscopy (SEM) using a Jeol JSM 6380 LA apparatus. Micrographs were recorded both on samples broken at liquid nitrogen temperature and specimens after tensile test.

\section{Results and discussion}

\subsection{Water absorption}

Capacity and rate of water ad- or absorption are the most important functional properties of desiccant composites. In the first part of the study, these quantities were determined for PLA, starch powders and PLA/starch composites from the water uptake curves. Water absorption isotherms of starch powders ( $\mathrm{S} 0$, S24, S47) measured at 50 and $100 \% R H$ are presented in Figure 1, respectively. According to Figure 1, the absorption of water by desiccants was relatively fast, and starch powders (S0, S24, S47) absorbed 11.39, 9.01 and $13.75 \%$ of their weights at $50 \% R H$, while $23.09,66.60$ and $77.09 \%$ at $100 \% R H$. We regard these values as the theoretical capacity of the investigated starch powders under our conditions. As the figures show, water uptake of starch powders determined at $100 \% R H$ increased proportionally with glycerol content, but at $50 \% R H$ the correlation between water uptake capacity and glycerol content is not clear, the smallest capacity was measured for S24, the largest for S47. A similar result was found in the literature [48]. There is some uncertainty in the measured capacities of the powders at $100 \% \mathrm{RH}$, because the water uptake of S24 and S47 could be

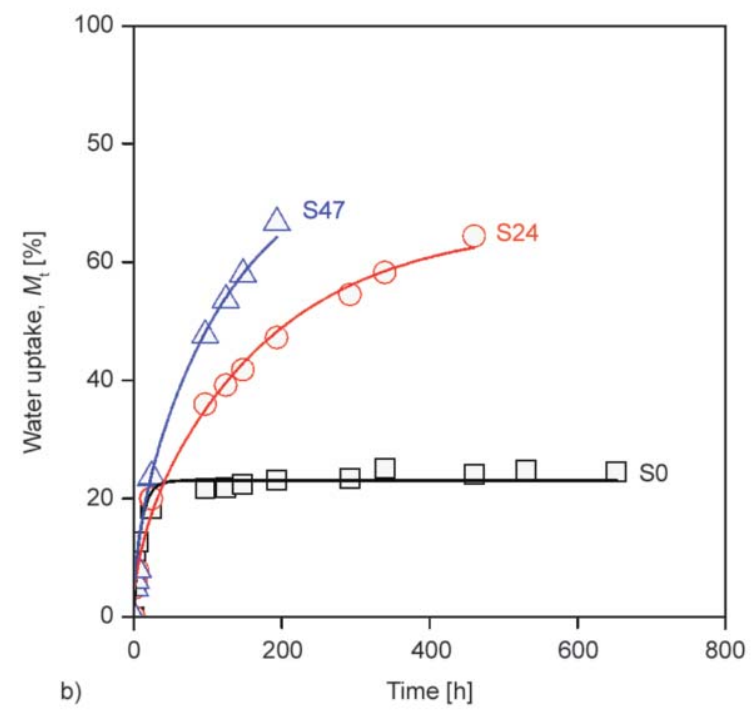

Figure 1. Water absorption curves of starch powders at different relative humidities, a) $50 \% R H$, b) $100 \% R H$. 

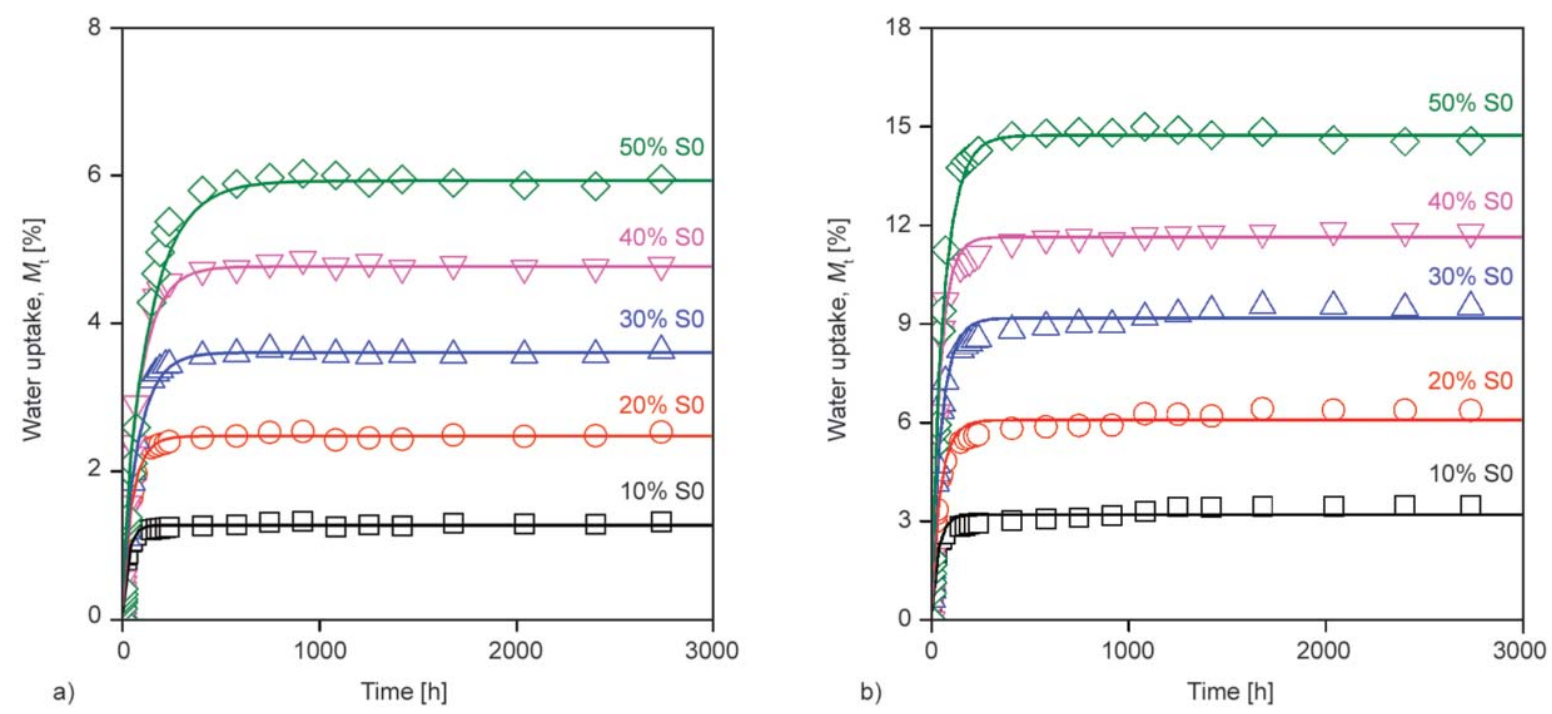

Figure 2. Water absorption curves of PLA/S0 composites at different relative humidities, a) $50 \% R H$, b) $100 \% R H$.

measured only until 400 and 200 hours, respectively, since after these times water condensed on the powders.

The water uptake of all the PLA/unplasticized starch (S0) composites is presented as a function of time in Figure 2 (Figure 2a: $50 \% R H$, Figure $2 \mathrm{~b}: 100 \% R H$ ). From the figures it is clear that the maximum absorption was proportional to the starch content and to the relative humidity as well, and was smaller than the capacity of the neat starch powder. The shape of water absorption curves was similar for PLA, starch powders and PLA/S0 composites, thus saturation type correlation was recorded in all cases. As we mentioned above, the capacity and rate of water absorption are the most important functional properties of desiccants and their composites with PLA. During the quantitative evaluations to determine capacity and overall rate, we assumed Fickian absorption, and Equation (1) (derived from Fick's second law [50]):

$\frac{M_{\mathrm{t}}}{M_{\infty}}=1-\frac{8}{\pi^{2}} \sum_{\mathrm{m}=0}^{\infty} \frac{1}{(2 m+1)^{2}} \exp \left[-\frac{D(2 m+1)^{2} \pi^{2} t}{L^{2}}\right]$

was solved for $m=2$ to obtain the following correlation shown in Equation (2):

$$
\begin{aligned}
M_{\mathrm{t}} & =M_{\infty}\left(1-\frac{8}{\pi^{2}}\left(\exp (-a t)+\frac{1}{9} \exp (-9 a t)+\right.\right. \\
& \left.\left.+\frac{1}{25} \exp (-25 a t)\right)\right)
\end{aligned}
$$

where $M_{\mathrm{t}}$ is the time dependent weight increase, $M_{\infty}$ the final water uptake reached after infinite time (absorption capacity), $D$ the diffusion coefficient, $L$ the thickness of the sample, $t$ the time of absorption, and $a$ is a constant characterizing the overall rate of water absorption. We also determined the initial rate of absorption from a different form of Fick's law [50] (see Equation (3)):

$$
\frac{M_{\mathrm{t}}}{M_{\infty}}=4\left(\frac{D t}{L^{2}}\right)^{1 / 2}\left(\pi^{-1 / 2}+2 \sum_{\mathrm{m}=0}^{\infty}(-1)^{\mathrm{m}} \operatorname{ierfc} \frac{m L}{2(D t)^{1 / 2}}\right)
$$

If we plot the water uptake as a function of the square root of time, we should obtain a straight line, the slope of which, $b$ is proportional to the initial rate of water absorption. Capacities, initial and overall rates were calculated for PLA, starch powders and all $\mathrm{PLA} / \mathrm{S} 0$ composites. The results are collected in Table 1 and Table 2, respectively.

The results of Table 1 show clearly that while the water absorption capacity of PLA was much smaller than that of the starch powders, as expected, surprisingly the initial and overall rates of PLA exceeded those of the desiccants. In addition, the glycerol content also decreased both rates of starch. We can

\begin{tabular}{|c|c|c|c|c|c|c|}
\hline \multirow{3}{*}{ 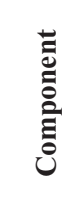 } & \multicolumn{6}{|c|}{$\begin{array}{c}\text { Relative humidity } \\
{[\%]}\end{array}$} \\
\hline & \multicolumn{3}{|c|}{50} & \multicolumn{3}{|c|}{100} \\
\hline & $\begin{array}{l}M_{\infty} \\
{[\%]}\end{array}$ & $\begin{array}{c}a \cdot 10^{6} \\
{\left[\mathrm{~s}^{-1}\right]}\end{array}$ & $\begin{array}{l}b \cdot 10^{3} \\
{\left[\mathbf{s}^{-1 / 2}\right]}\end{array}$ & $\begin{array}{l}M_{\infty} \\
{[\%]}\end{array}$ & $\begin{array}{c}a \cdot 10^{6} \\
{\left[\mathrm{~s}^{-1}\right]}\end{array}$ & $\begin{array}{l}b \cdot 10^{3} \\
{\left[s^{-1 / 2}\right]}\end{array}$ \\
\hline S0 & 11.39 & 9.46 & 2.22 & 23.09 & 26.70 & 4.43 \\
\hline S24 & 9.01 & 5.64 & 1.78 & 66.60 & 1.55 & 1.01 \\
\hline S47 & 13.75 & 4.22 & 1.48 & 79.09 & 2.10 & 0.99 \\
\hline PLA & 0.33 & 16.01 & 3.67 & 0.79 & 15.18 & 7.53 \\
\hline
\end{tabular}

Table 1. Capacities, overall $(a)$ and initial $(b)$ rates of water absorption of starch powders and PLA. 
Table 2. Capacities, overall $(a)$ and initial $(b)$ rates of water absorption of PLA/starch (S0) composites.

\begin{tabular}{|c|c|c|c|c|c|c|}
\hline \multirow{3}{*}{$\begin{array}{l}\text { Starch } \\
\text { content } \\
{[\mathrm{v} / \mathrm{v} \%]}\end{array}$} & \multicolumn{6}{|c|}{$\begin{array}{c}\text { Relative humidity } \\
{[\%]}\end{array}$} \\
\hline & \multicolumn{3}{|c|}{50} & \multicolumn{3}{|c|}{100} \\
\hline & $\begin{array}{l}M_{\infty} \\
{[\%]}\end{array}$ & $\begin{array}{c}a \cdot 10^{6} \\
{\left[\mathrm{~s}^{-1}\right]}\end{array}$ & $\begin{array}{l}b \cdot 10^{3} \\
{\left[\mathrm{~s}^{-1 / 2}\right]}\end{array}$ & $\begin{array}{c}M_{\infty} \\
{[\%]}\end{array}$ & $\begin{array}{c}a \cdot 10^{6} \\
{\left[\mathrm{~s}^{-1}\right]}\end{array}$ & $\begin{array}{c}b \cdot 10^{3} \\
\left.\left[\mathrm{~s}^{-1 / 2}\right]\right)\end{array}$ \\
\hline 10 & 1.27 & 9.06 & 2.18 & 3.20 & 7.51 & 2.09 \\
\hline 20 & 2.48 & 4.94 & 1.52 & 6.08 & 5.46 & 1.69 \\
\hline 30 & 3.61 & 3.13 & 1.01 & 9.18 & 4.90 & 1.62 \\
\hline 40 & 4.77 & 2.89 & 1.01 & 11.65 & 5.73 & 1.54 \\
\hline 50 & 5.93 & 1.87 & 0.69 & 14.74 & 3.92 & 1.21 \\
\hline
\end{tabular}

suppose that the reason of the large difference between the water diffusion rates of PLA and starch originated from the dissimilar free volume of the two polymers [51].

The results of Table 2, which were determined for $\mathrm{PLA} / \mathrm{S} 0$ composites, prove that the equilibrium water uptake $\left(M_{\infty}\right)$ increased with starch content, but the absorption rates decreased as a function of starch loading. Similarly to the results presented in Table 1 for PLA and starch powders, the initial and overall rates of water uptake of composites were lower than that of PLA or starch powder.

The evaluation of water absorption curves of PLA/ starch-glycerol (S24, S47) composites proved to be more difficult than it was in the case of PLA/starch composites. The water uptake of most of these composites did not show saturation type correlation with time, but the water uptake reached a maximum after some hours and then it began to decrease. The extent of weight loss depends on the glycerol content of

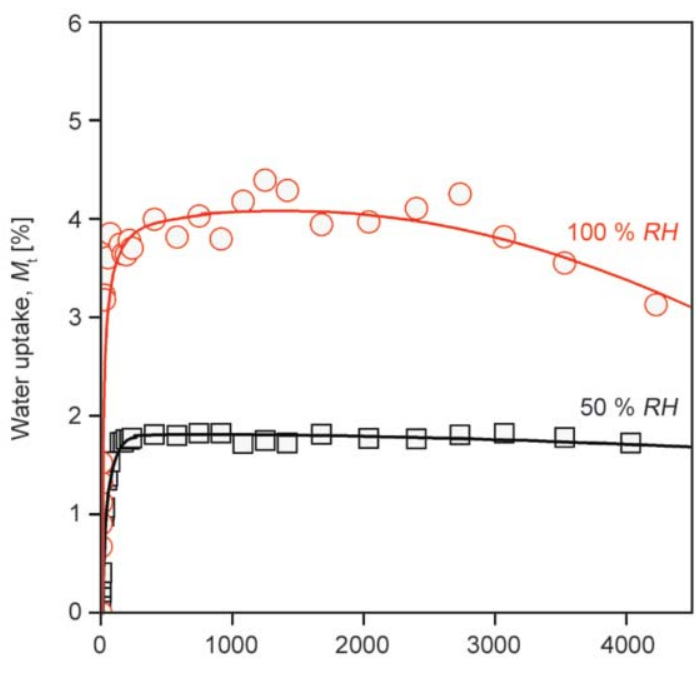

a)

Time [h] composites and the relative humidity. In Figure 3 the water uptake curves of PLA/S24 composites containing $20 \mathrm{v} / \mathrm{v} \%$ S24 (Figure 3a) and $50 \mathrm{v} / \mathrm{v} \%$ S24 (Figure $3 \mathrm{~b}$ ) indicate that both higher desiccant content (more glycerol in the composite) and higher relative humidity resulted in larger weight loss. In the case of PLA/S47 systems the weight loss was more pronounced. According to these results, we presume that glycerol migration caused the measured weight loss. In order to prove this assumption, we studied the morphology and the glass transition temperatures $\left(T_{\mathrm{g}}\right)$ of PLA/S24 and PLA/S47 systems before and after water absorption measurements. In Figure 4 we present the SEM micrographs of PLA/S47 composites containing $50 \mathrm{v} / \mathrm{v} \%$ desiccant, before and after water uptake. According to the photos, the fracture surface was much rougher after the absorption test than that one determined before the test. Similar results were found for all composites containing glycerol. On the bases of these results the migration of glycerol was presumed properly, since only the lack of plasticizer could result in such a rough morphology in PLA/ starch composites. In Figure 5, the temperature dependence of loss tangent $(\operatorname{tg} \delta)$ of dry and conditioned (at 100\% RH) PLA/S47 samples containing $50 \mathrm{v} / \mathrm{v} \%$ TPS 47 also proved the glycerol migration. Although the $T_{\mathrm{g}}$ and cold crystallization temperature of PLA at $60-80^{\circ} \mathrm{C}$ were unchanged, the $T_{\mathrm{g}}$ of TPS increased from around -10 to $30^{\circ} \mathrm{C}$ as a result of the decreased glycerol content. Our former results also showed that the transition temperatures of PLA did not depend on the glycerol content of TPS in PLA/

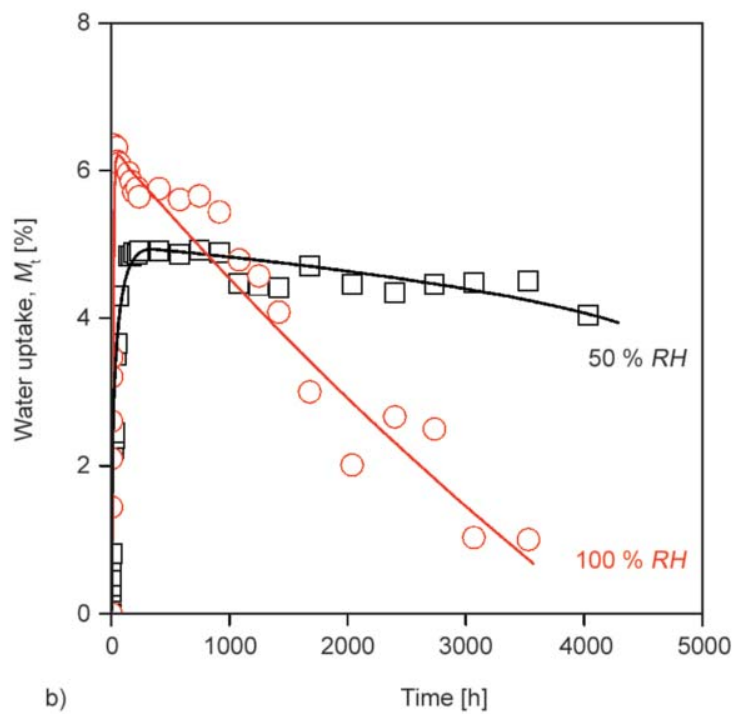

Figure 3. Water absorption curves of PLA/S24 composites at different values of relative humidity, a) $20 \mathrm{v} / \mathrm{v} \%$, b) $50 \mathrm{v} / \mathrm{v} \%$. 


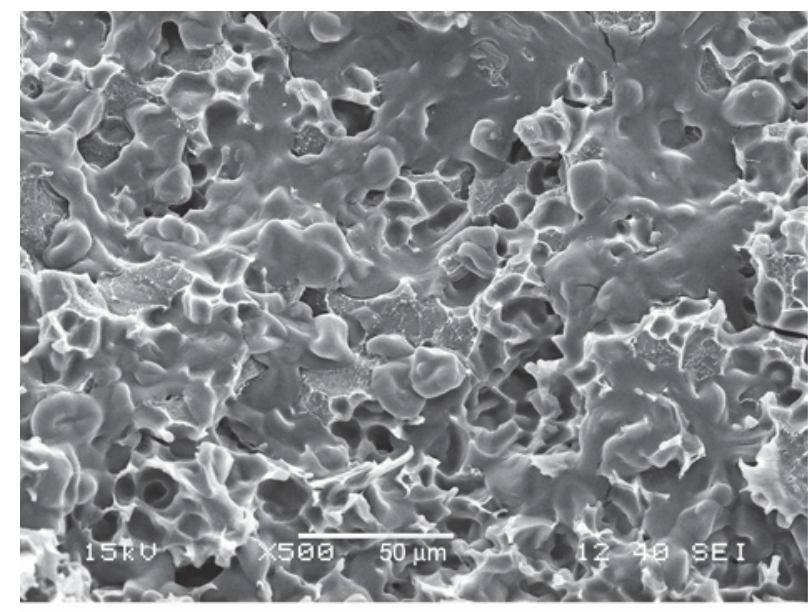

a)

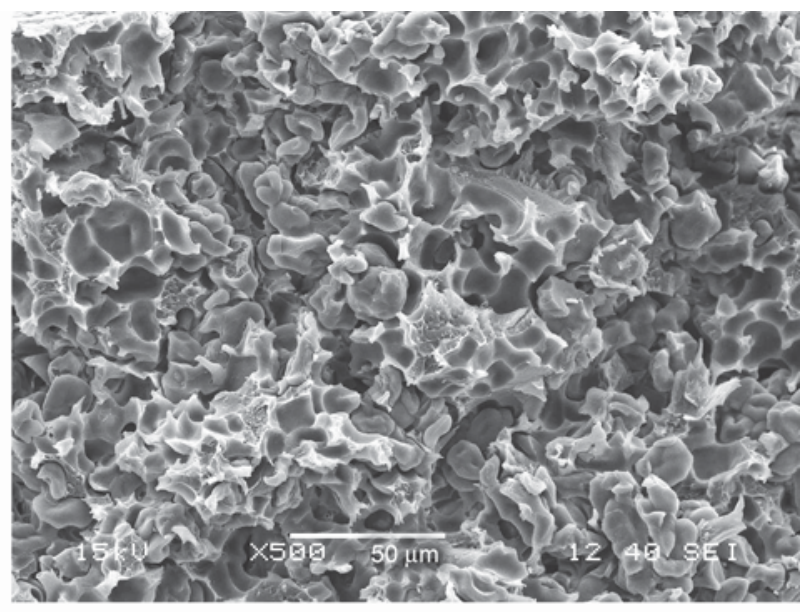

b)

Figure 4. SEM micrograph of PLA/S47 composites containing $50 \mathrm{v} / \mathrm{v} \% \mathrm{~S} 47$ recorded before (a) and after (b) water uptake measurements $(100 \% R H)$.

TPS composites, while the $T_{\mathrm{g}}$ of TPS depended strongly on polyol content and the composition of the composite, respectively [49]. One goal of our study was to determine the effect of glycerol content on the parameters of water absorption of starch desiccants. Although we could examine this effect in the case of starch powders, unfortunately, for composites it was not feasible because of the previously mentioned glycerol migration.

According to the results presented above, only PLA/ unplasticized starch composites may be a suitable inner container in the packaging of drugs or dry foods. Furthermore, the incorporation of starch and its high water uptake may improve the biodegradability of PLA after the application.

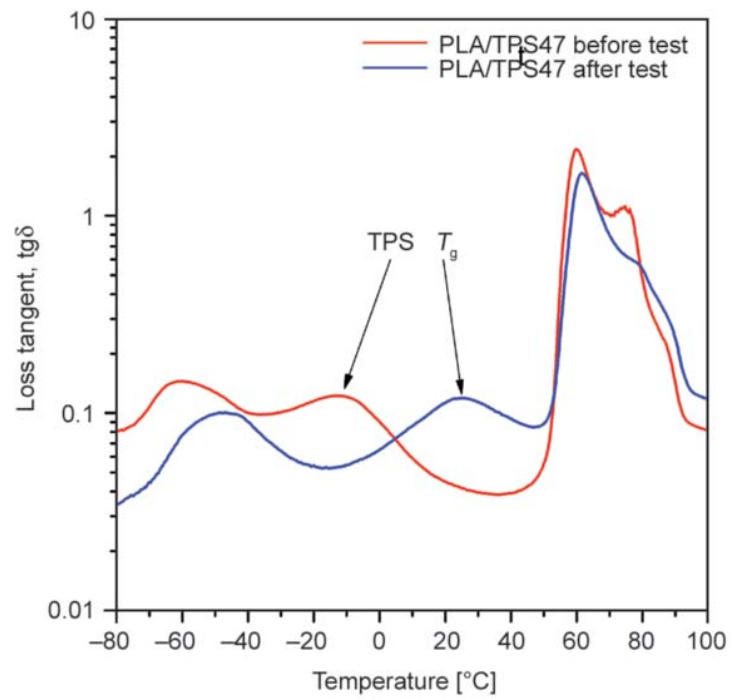

Figure 5. DMA curves showing the relaxation transitions of PLA/TPS47 (50 v/v\%) composites before and after the water absorption test.

\subsection{Mechanical properties}

Although the capacity and rate of water absorption are the dominant functional characteristics of desiccant composites, mechanical properties are also very important for the application of these composites as packaging materials. The most important mechanical properties related to the stiffness, strength and deformability of PLA/starch (S0) and PLA/starch-glycerol (S12, S24, S36, S47) composites were determined as a function of desiccant loading. The composition dependence of Young's modulus, tensile strength and elongation-at-break values of the investigated composites is plotted in Figure 6.

It is clear from Figure 6 that mechanical properties could be measured with significant accuracy; the standard deviation of the measurements is relatively small in the case of modulus and tensile strength. Considerable reinforcement was found in PLA/starch (S0) composites as both stiffness and strength of $\mathrm{PLA} / \mathrm{S} 0$ composites increased with increasing starch content. The reason of the reinforcement can be related to the good stress transfer between the components due to the strong interfacial interactions or the small particle size of starch powder. The addition of glycerol to starch, however, changed the composition dependence of the modulus and tensile strength of the composites. The figures clearly show that both the modulus and tensile strength of PLA/starch-glycerol systems decreased with increasing desiccant content with an exception of PLA/S12 composites. The stiffness of these composites did not change significantly with increasing starch content. According to Figure $6 \mathrm{a}$ and Figure 6b, respectively, the composition dependence of the modulus and tensile strength 
of S12 and S24 composites were very similar, and so were the mechanical properties of the S36 and
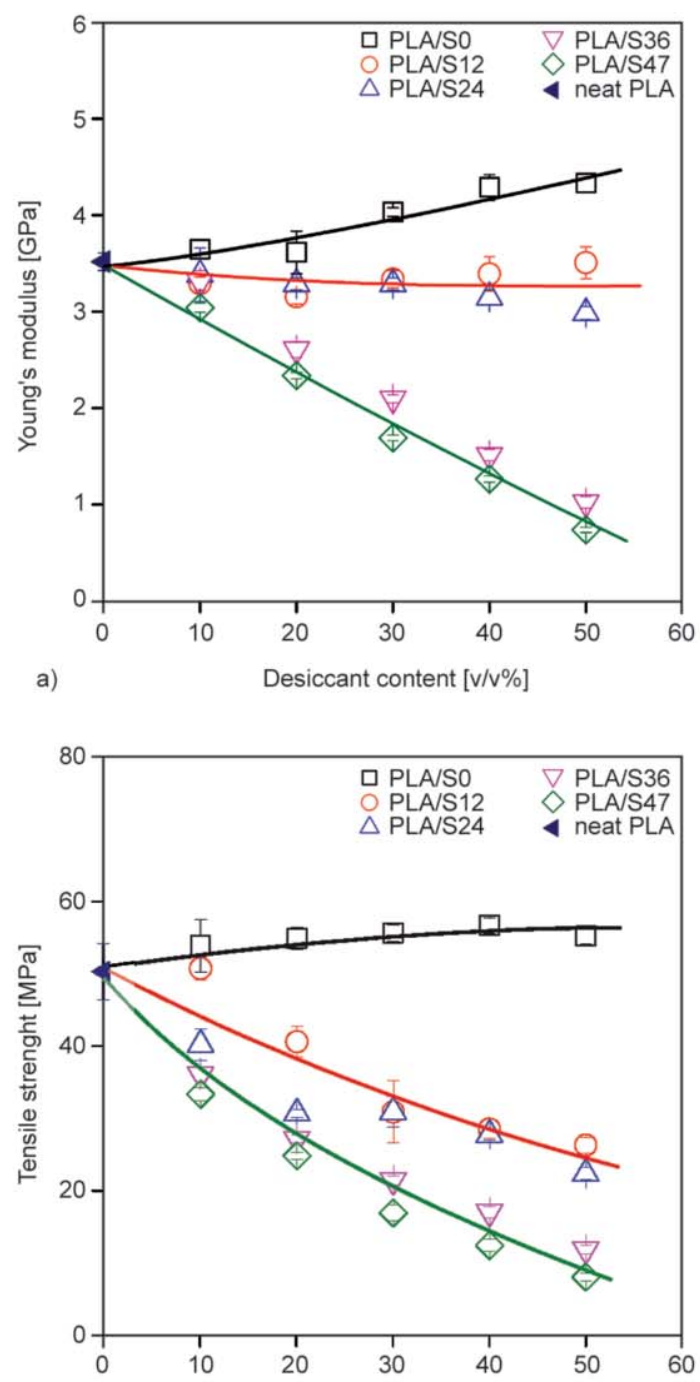

b)

Desiccant content [v/v\%]

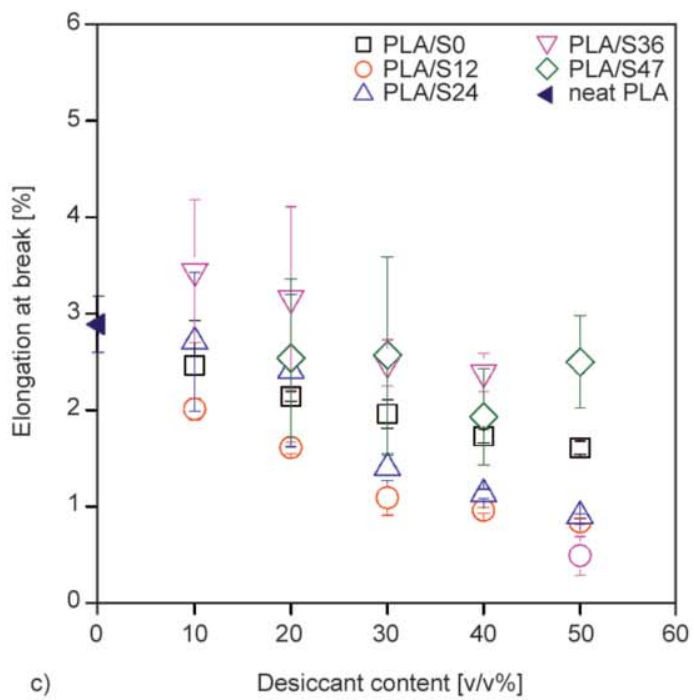

Figure 6. Mechanical properties of PLA/starch (S0, S12, S24, S36, S47) composites, a) Young's modulus, b) tensile strength, c) elongation at break.
S47 systems. This might be an indirect evidence of structural similarities which we discuss later. Larger desiccant amount resulted in smaller elongation-atbreak for all composites; however, it is difficult to determine any correlation between the extent of the decrease and the glycerol content of the starch powders because of the large standard deviation of this deformability.

\subsection{Morphology of the desiccant composites}

In this section we discuss the results of scanning electron microscopy with a focus on the effect of glycerol content on the morphology, and on the influence of morphology on the stiffness and strength of the composites. Figure 7 shows micrographs recorded on the tensile fracture surface of selected composites. SEM micrographs were prepared to reveal or at least supply some additional information about the mechanism of failure, the structure and interfacial interactions in our PLA/starch composites. In heterogeneous polymer systems, stress concentration develops around the particles under the effect of external load and the actual stress distribution determines the local micromechanical deformation processes [52]. These competitive micromechanical deformation processes take place simultaneously in composites. In particulate filled polymers the dominating deformation mechanism is the separation of the matrix/filler interface, i.e. debonding, which usually leads to void formation and volume increase during deformation [53]. Debonding takes place when the energy resulting from the change of elastic deformation is equal or larger than the work necessary to create new surfaces. Earlier experience on natural filler reinforced composites shows that weak interaction and large particle size lead to debonding [54], which is initiated at very small stresses. The dominating process in the studied PLA/starch composites might have been debonding, with a limited number of particle fractures because of the weak interactions between matrix and filler. However, the number of these latter was much smaller than that of the debonded particles. Glycerol might have changed at least two important factors determining the properties of PLA/starchglycerol systems: the strength of interfacial interactions between PLA and starch, and the inherent strength of starch particles. As the glycerol content of starch increased, the dominating deformation process changed, and particle fracture was hindered by the weak adhesion between the matrix and the filler. 


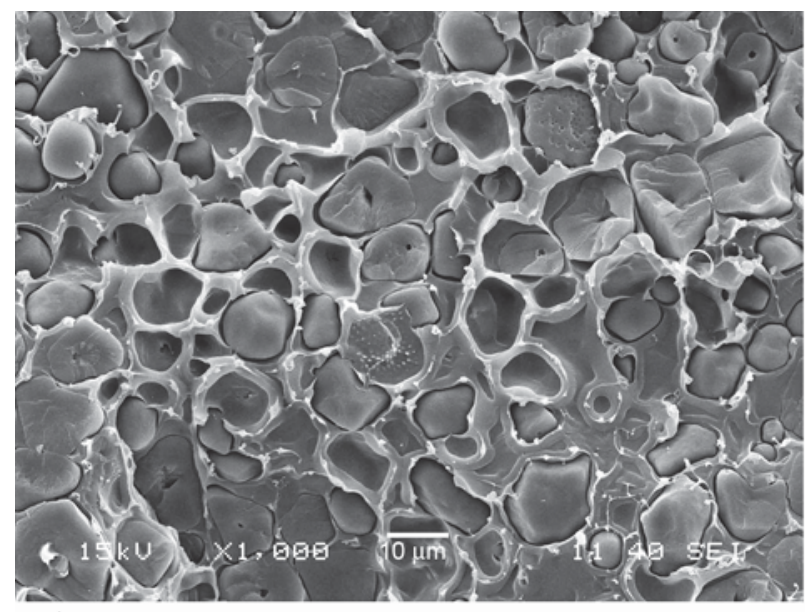

a)

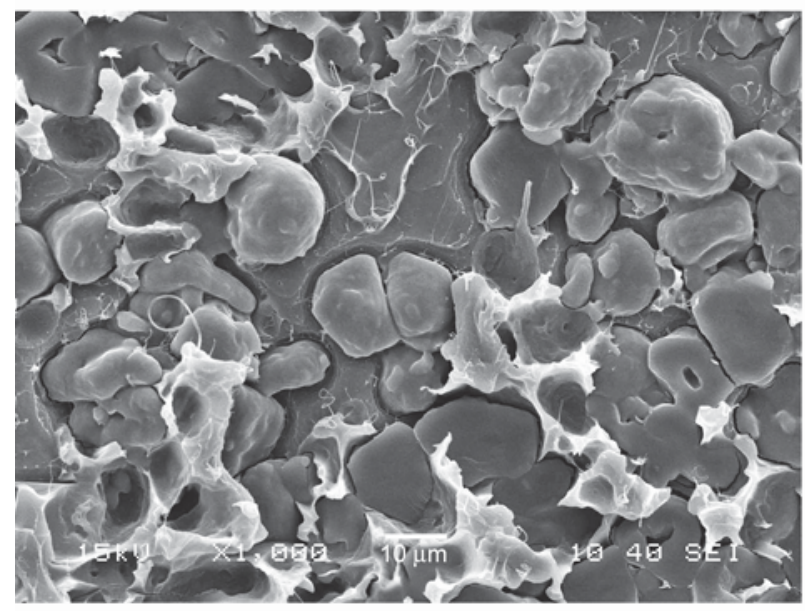

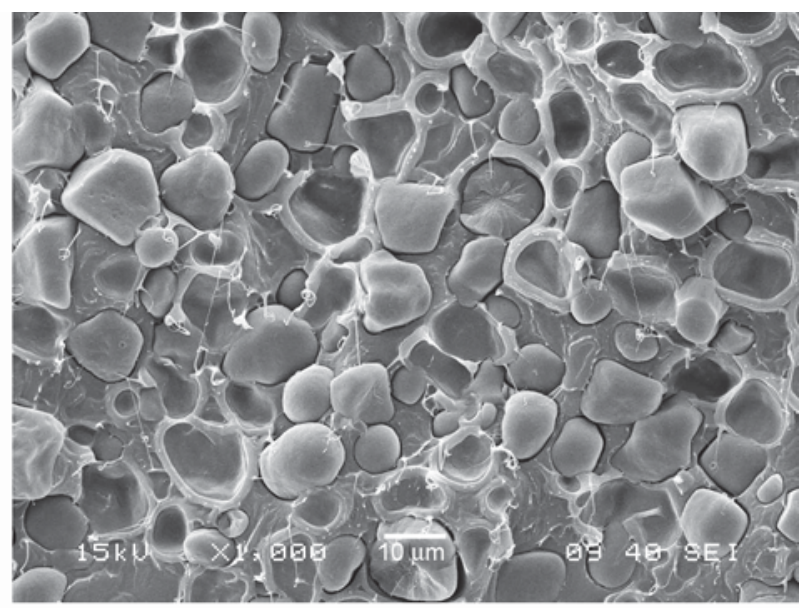

b)

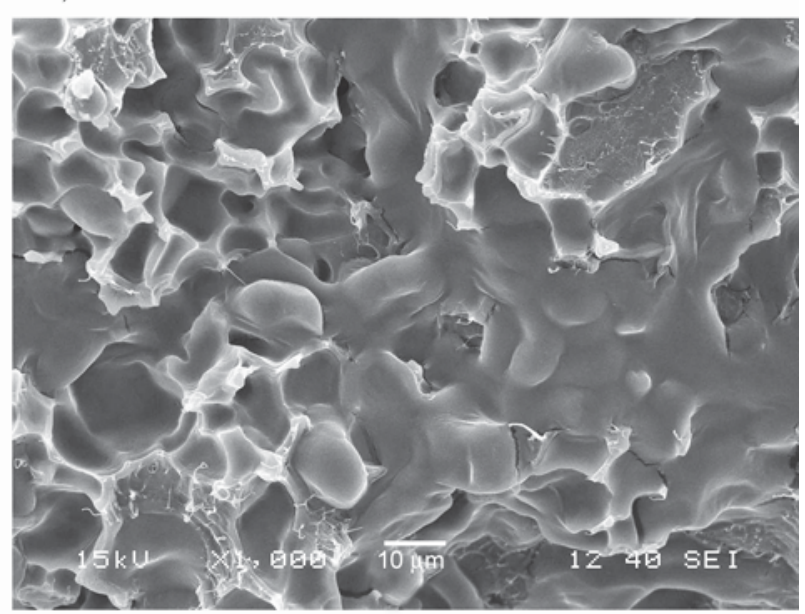

d)

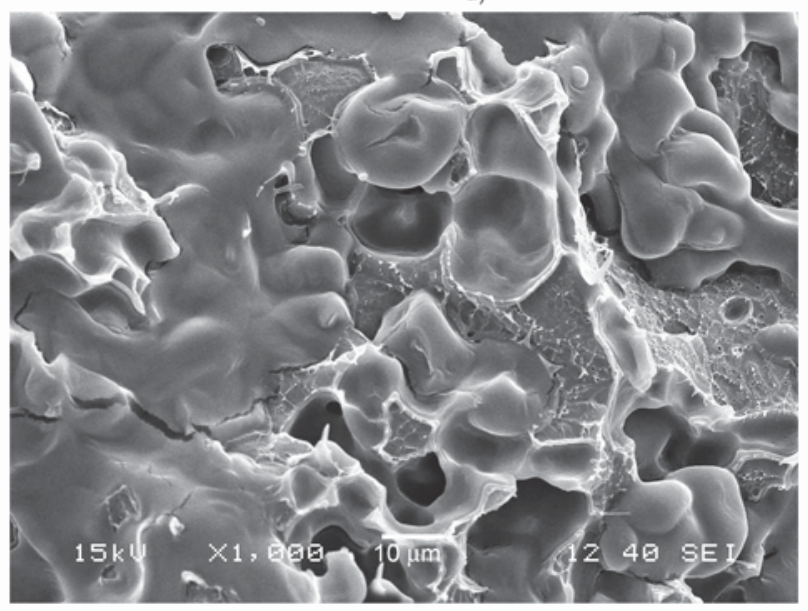

e)

Figure 7. SEM micrographs of PLA/starch composites containing $50 \mathrm{v} / \mathrm{v} \%$ desiccant; a) PLA/S0, b) PLA/ S12, c) PLA/S24, d) PLA/S36, e) PLA/S47.

Particle size and particle shape also changed with increasing glycerol content. Plasticized starch particles seem to have larger size as a result of glycerol absorption and the diffusion of the plastizicer into the starch particles. In order to check this assumption we determined the particle size of starch and selected (S12, S24) starch-glycerol powders. The results of particle size measurement are shown in Table 3. It can be seen that the volume average particle size $(\mathrm{D}[4,3])$ of the powders increased with increasing glycerol content. The largest average particle size was determined for S24 powder which was more than two times larger than the particle size of the pure starch powder (S0). Unfortunately, we were unable to measure the particle size distribution of starch-glycerol powders with large glycerol content 
Table 3. Particle characteristics of the studied starch powders.

\begin{tabular}{|l|c|c|c|c|}
\hline \multicolumn{1}{|c|}{ Sample } & $\begin{array}{c}\mathbf{d}(\mathbf{0 . 1}) \\
{[\boldsymbol{\mu m}]}\end{array}$ & $\begin{array}{c}\mathbf{d}(\mathbf{0 . 5}) \\
{[\boldsymbol{\mu m}]}\end{array}$ & $\begin{array}{c}\mathbf{d}(\mathbf{0 . 9}) \\
{[\boldsymbol{\mu m}]}\end{array}$ & $\begin{array}{c}\mathbf{D}[\mathbf{4 , 3}] \\
{[\boldsymbol{\mu m}]}\end{array}$ \\
\hline Starch powder & 10.773 & 17.212 & 26.303 & 18.184 \\
\hline S12 powder & 13.623 & 20.859 & 30.805 & 21.719 \\
\hline S24 powder & 26.293 & 41.860 & 68.412 & 45.413 \\
\hline
\end{tabular}

(larger than $24 \mathrm{wt} \%$ of glycerol), because the particles became sticky and adhered to each other.

As the glycerol content increases, the stiffness of TPS decreases [48, 49, 55], which results in the softening of TPS particles. In our case, at higher glycerol content starch particles softened at the relatively high temperature of processing, and they started to coalesce resulting in a less uniform particle size and shape (Figure $7 \mathrm{~d}$ and Figure $7 \mathrm{e}$ ). The shear forces acting during processing were not large enough to break up these united particles, therefore at $50 \mathrm{v} / \mathrm{v} \%$ starch content the deformation of these partially plasticized, soft particles led to the development of a quasi-cocontinuous structure in the case of PLA/S36 and PLA/S47 composites. This observation indicates that PLA and plasticized starch rather formed a blend than a composite at large glycerol content. The similar morphology of the composites containing S12 and S24 desiccant resulted in the similarity of the composition dependence of their modulus and tensile strength. The same correlation also can be found between the stiffness and strength of PLA/S36 and PLA/S47 blends.

\section{Conclusions}

The study of PLA/starch and PLA/starch-glycerol composites showed that starch could absorb a considerable amount of water in PLA, thus the absorption capacity of PLA/unplasticized starch composites were close to the patented and commonly applied polymer/zeolite desiccant composites [51]. The diffusion of water into PLA/starch composites obeyed Fick's laws, so the amount of absorbed water plotted against time gave a saturation curve. Furthermore, the absorption capacity of these composites increased significantly with increasing starch content and relative humidity, respectively. Unplasticized starch had not only a desiccant but also a reinforcing effect in PLA, thus stiffness and strength increased with increasing starch loading. According to the literature, increased water absorption capacity results in the enhanced biodegradability of PLA. All these results imply that, on the one hand, PLA/unplasticized starch composites may be adequate as a biodegradable inner container in drug or dry food packaging. On the other hand, PLA containing glycerol-plasticized starch is not suitable for this purpose because of the glycerol migration. Although the absorption capacity of starch-glycerol powders exceeded that of starch powder, the additional glycerol did not increase the equilibrium water uptake of the desiccant composites. The smaller water absorption of PLA/starchglycerol composites compering with the PLA/starch composites can be explained by the migration of glycerol from the bulk to the surface of the composites. The SEM micrographs recorded on the tensile fracture surface of the composites indicated only moderate interfacial adhesion between the components. The dominating deformation process was definitely debonding, the separation of the matrix and the filler at the interface under the effect of external load, with few observable particle fractures. The addition of glycerol weakened the PLA/starch adhesion and softened starch particles resulting in the change of the morphology and the dominating deformation mechanism determining the failure of composites. At large glycerol content a quasi-co-continuous structure developed, which indicates that the homogenization of PLA and plasticized starch resulted in a blend rather than a composite. As a result, plasticized starch had no reinforcing effect in PLA.

\section{Acknowledgements}

The authors are indebted to Ferenc Verasztó for the preparation of composites and the measurements of water uptake. The financial support of the National Scientific Research Fund of Hungary (OTKA Grant No. K 108934) is highly appreciated.

\section{References}

[1] Yam K. L.: The Wiley encyclopedia of packaging technology. Wiley, Hoboken (2009).

[2] Rooney M. L.: Active food packaging. Chapmann and Hall, Glasgow (1995)

[3] Brody A. L., Strupinsky E. R., Kline L. R.: Active packaging for food applications. CRC Press, London (2001).

[4] Summer L.: Intelligent packaging. Centre for Exploitation of Science and Technology, London (1992).

[5] Ahvenainen R.: Novel food packaging techniques. Woodhead, Cambridge (2003).

[6] Mahajan P. V., Rodrigues F. A. S., Motel A., Leonhard A.: Development of a moisture absorber for packaging of fresh mushrooms (Agaricus bisporous). Postharvest Biology and Technology, 48, 408-414 (2008). https://doi.org/10.1016/j.postharvbio.2007.11.007 
[7] Sandhya: Modified atmosphere packaging of fresh produce: Current status and future needs. LWT - Food Science and Technology, 43, 381-392 (2010).

https://doi.org/10.1016/j.1wt.2009.05.018

[8] Allinson J. G., Dansereau R. J., Sakr A.: The effects of packaging on the stability of a moisture sensitive compound. International Journal of Pharmaceutics, 221, 49$56(2001)$. https://doi.org/10.1016/S0378-5173(01)00670-6

[9] Waterman K. C., MacDonald B. C.: Package selection for moisture protection for solid, oral drug products. Journal of Pharmaceutical Sciences, 99, 4437-4452 (2010). https://doi.org/10.1002/jps.22161

[10] Naveršnik K., Bohanec S.: Predicting drug hydrolysis based on moisture uptake in various packaging designs. European Journal of Pharmaceutical Sciences, 35, 447 456 (2008). https://doi.org/10.1016/j.ejps.2008.09.007

[11] Wong E. H., Rajoo R.: Moisture absorption and diffusion characterisation of packaging materials - Advanced treatment. Microelectronics Reliability, 43, 2087-2096 (2003). https://doi.org/10.1016/S0026-2714(03)00378-0

[12] Ovoshchnikov D. S., Glaznev I. S., Aristov Y. I.: Water sorption by the calcium chloride/silica gel composite: The accelerating effect of the salt solution present in the pores. Kinetics and Catalysis, 52, 620-628 (2011). https://doi.org/10.1134/S0023158411040124

[13] Nji J., Li G.: A CaO enhanced rubberized syntactic foam. Composites Part A: Applied Science and Manufacturing, 39, 1404-1411 (2008).

https://doi.org/10.1016/j.compositesa.2008.05.001

[14] Spahis N., Dellali M., Mahmoudi H.: Synthesis and characterization of polymeric/activated carbon membranes. Procedia Engineering, 33, 47-51 (2012). https://doi.org/10.1016/j.proeng.2012.01.1175

[15] Ragosta G., Abbate M., Musto P., Scarinzi G., Mascia L.: Epoxy-silica particulate nanocomposites: Chemical interactions, reinforcement and fracture toughness. Polymer, 46, 10506-10516 (2005).

https://doi.org/10.1016/j.polymer.2005.08.028

[16] Liu Q., De Kee D., Gupta R. K.: Models of moisture diffusion through vinyl ester/clay nanocomposites. Aiche Journal, 54, 364-371 (2008). https://doi.org/10.1002/aic.11374

[17] Mathiowitz E., Jacob J. S., Jong Y. S., Hekal T. M., Spano W., Guemonprez R., Klibanov A. M., Langer R.: Novel desiccants based on designed polymeric blends. Journal of Applied Polymer Science, 80, 317-327 (2001).

https://doi.org/10.1002/1097-4628(20010418)80:3<317::aidapp1102>3.0.co;2-q

[18] Pehlivan H., Özmihçi F., Tihminlioğlu F., Balköse D., Ülkü S.: Water and water vapor sorption studies in polypropylene-zeolite composites. Journal of Applied Polymer Science, 90, 3069-3075 (2003).

https://doi.org/10.1002/app.13046
[19] Aristov Y. I., Glaznev I. S., Freni A., Restuccia G.: Kinetics of water sorption on SWS-1L (calcium chloride confined to mesoporous silica gel): Influence of grain size and temperature. Chemical Engineering Science, 61, 1453-1458 (2006).

https://doi.org/10.1016/j.ces.2005.08.033

[20] Gordeeva L. G., Grekova A. D., Krieger T. A., Aristov Y. I.: Adsorption properties of composite materials $(\mathrm{LiCl}+\mathrm{LiBr}) /$ silica. Microporous and Mesoporous Materials, 126, 262-267 (2009).

https://doi.org/10.1016/j.micromeso.2009.06.015

[21] Manek R. V., Kunle O. O., Emeje M. O., Builders P., Rao G. V. R., Lopez G. P., Kolling W. M.: Physical, thermal and sorption profile of starch obtained from Tacca leontopetaloides. Starch, 57, 55-61 (2005). https://doi.org/10.1002/star.200400341

[22] Mali S., Sakanaka L. S., Yamashita F., Grossmann M. V. E.: Water sorption and mechanical properties of cassava starch films and their relation to plasticizing effect. Carbohydrate Polymers, 60, 283-289 (2005). https://doi.org/10.1016/j.carbpol.2005.01.003

[23] Sohn O., Kim D.: Theoretical and experimental investigation of the swelling behavior of sodium polyacrylate superabsorbent particles. Journal of Applied Polymer Science, 87, 252-257 (2003).

https://doi.org/10.1002/app.11360

[24] Yoshimura T., Uchikoshi I., Yoshiura Y., Fujioka R.: Synthesis and characterization of novel biodegradable superabsorbent hydrogels based on chitin and succinic anhydride. Carbohydrate Polymers, 61, 322-326 (2005). https://doi.org/10.1016/j.carbpol.2005.06.014

[25] Zhang J., Yuan K., Wang Y-P., Gu S-J., Zhang S-T.: Preparation and properties of polyacrylate/bentonite superabsorbent hybrid via intercalated polymerization. Materials Letters, 61, 316-320 (2007). https://doi.org/10.1016/j.matlet.2006.04.055

[26] Kono H., Fujita S.: Biodegradable superabsorbent hydrogels derived from cellulose by esterification crosslinking with 1,2,3,4-butanetetracarboxylic dianhydride. Carbohydrate Polymers, 87, 2582-2588 (2012). https://doi.org/10.1016/j.carbpol.2011.11.045

[27] Hekal I. M.: Desiccant entrained polymer. WO1999063288A1, Word Patent (1999).

[28] Kawaguchi Y., Fujimori M., Uchibori T., Ohyama K., Nishino A.: Moisture absorbing formed article. EP1788034 A2, EU (2007).

[29] Macchi G., Colombo A., Vacca P., Giannantonio R.: Desiccant composition for moisture-sensitive electronic devices. WO2013153469A1, Word Patent (2014).

[30] Ladisch M. R., Dyck K.: Dehydration of ethanol: New approach gives positive energy balance. Science, 205, 898-900 (1979).

https://doi.org/10.1126/science.205.4409.898

[31] Hong J., Voloch M., Ladisch M. R., Tsao G. T.: Adsorption of ethanol-water mixtures by biomass materials. Biotechnology and Bioengineering, 24, 725-730 (1982). https://doi.org/10.1002/bit.260240314 
[32] Westgate P. J., Ladisch M. R.: Sorption of organics and water on starch. Industrial and Engineering Chemistry Research, 32, 1676-1680 (1993).

https://doi.org/10.1021/ie00020a020

[33] Westgate P., Lee J. Y., Ladisch M. R.: Modeling of equilibrium sorption of water vapor on starch materials. Transactions of the American Society of Agricultural Engineers, 35, 213-219 (1992).

https://doi.org/10.13031/2013.28590

[34] Beery K. E., Ladisch M. R.: Chemistry and properties of starch based desiccants. Enzyme and Microbial Technology, 28, 573-581 (2001).

https://doi.org/10.1016/s0141-0229(00)00345-8

[35] Ladisch M. R., Voloch M., Hong J., Bienkowski P., Tsao G. T.: Cornmeal adsorber for dehydrating ethanol vapors. Industrial and Engineering Chemistry Process Design and Development, 23, 437-443 (1984). https://doi.org/10.1021/i200026a005

[36] Yew G. H., Mohd Yusof A. M., Mohd Ishak Z. A., Ishiaku U. S.: Water absorption and enzymatic degradation of poly(lactic acid)/rice starch composites. Polymer Degradation and Stability, 90, 488-500 (2005). https://doi.org/10.1016/j.polymdegradstab.2005.04.006

[37] Yew G. H., Chow W. S., Mohd Ishak Z. A., Mohd Yusof A. M.: Natural weathering of poly (lactic acid): Effects of rice starch and epoxidized natural rubber. Journal of Elastomers \& Plastics, 41, 369-382 (2009). https://doi.org/10.1177/0095244309103663

[38] Rodrigues C. A., Tofanello A., Nantes I. L., Rosa D. S.: Biological oxidative mechanisms for degradation of poly(lactic acid) blended with thermoplastic starch. ACS Sustainable Chemistry and Engineering, 3, 27562766 (2015).

https://doi.org/10.1021/acssuschemeng.5b00639

[39] Rocca-Smith J. R., Whyte O., Brachais C-H., Champion D., Piasente F., Marcuzzo E., Sensidoni A., Debeaufort F., Karbowiak T.: Beyond biodegradability of poly (lactic acid): Physical and chemical stability in humid environments. ACS Sustainable Chemistry and Engineering, 5, 2751-2762 (2017).

https://doi.org/10.1021/acssuschemeng.6b03088

[40] Siparsky G. L., Voorhees K. J., Dorgan J. R., Schilling K.: Water transport in polylactic acid (PLA), PLA/ polycaprolactone copolymers, and PLA/polyethylene glycol blends. Journal of Environmental Polymer Degradation, 5, 125-136 (1997).

https://doi.org/10.1007/BF02763656

[41] Gao H., Hu S., Su F., Zhang J., Tang G.: Mechanical, thermal, and biodegradability properties of PLA $/$ modified starch blends. Polymer Composites, 32, 2093 2100 (2011). https://doi.org/10.1002/pc.21241

[42] Zhang J-F., Sun X.: Mechanical properties of poly(lactic acid)/starch composites compatibilized by maleic anhydride. Biomacromolecules, 5, 1446-1451 (2004). https://doi.org/10.1021/bm0400022
[43] de M. Teixeira E., Curvelo A. A. S., Corrêa A. C., Marconcini J. M., Glenn G. M., Mattoso L. H. C.: Properties of thermoplastic starch from cassava bagasse and cassava starch and their blends with poly (lactic acid). Industrial Crops and Products, 37, 61-68 (2012). https://doi.org/10.1016/j.indcrop.2011.11.036

[44] Huneault M. A., Li H.: Morphology and properties of compatibilized polylactide/thermoplastic starch blends. Polymer, 48, 270-280 (2007). https://doi.org/10.1016/j.polymer.2006.11.023

[45] Li H. B., Huneault M. A.: Comparison of sorbitol and glycerol as plasticizers for thermoplastic starch in TPS/PLA blends. Journal of Applied Polymer Science, 119, 2439-2448 (2011).

https://doi.org/10.1002/app.32956

[46] le Bolay N., Lamure A., Leis N. G., Subhani A.: How to combine a hydrophobic matrix and a hydrophilic filler without adding a compatibilizer - Co-grinding enhances use properties of renewable PLA-starch composites. Chemical Engineering and Processing: Process Intensification, 56, 1-9 (2012). https://doi.org/10.1016/j.cep.2012.03.005

[47] Mathew A. P., Dufresne A.: Plasticized waxy maize starch: Effect of polyols and relative humidity on material properties. Biomacromolecules, 3, 1101-1108 (2002). https://doi.org/10.1021/bm020065p

[48] Avérous L.: Biodegradable multiphase systems based on plasticized starch: A review. Journal of Macromolecular Science Part C: Polymer Reviews, 44, 231-274 (2004). https://doi.org/10.1081/MC-200029326

[49] Müller P., Bere J., Fekete E., Móczó J., Nagy B., Kállay M., Gyarmati B., Pukánszky B.: Interactions, structure and properties in PLA/plasticized starch blends. Polymer, 103, 9-18 (2016).

https://doi.org/10.1016/j.polymer.2016.09.031

[50] Crank J., Park G. S.: Diffusion in polymers. Academic Press, London (1968).

[51] Kenyó C., Kajtár D. A., Renner K., Kröhnke C., Pukánszky B.: Functional packaging materials: Factors affecting the capacity and rate of water adsorption in desiccant composites. Journal of Polymer Research, 20, 1-8 (2013). https://doi.org/10.1007/s10965-013-0294-2

[52] Bucknall C. B.: Toughened plastics. Springer, London (1977).

[53] Pukánszky B., van Es M., Maurer F. H. J., Vörös G.: Micromechanical deformations in particulate filled thermoplastics: Volume strain measurements. Journal of Materials Science, 29, 2350-2358 (1994). https://doi.org/10.1007/BF00363426

[54] Dányádi L., Renner K., Móczó J., Pukánszky B.: Wood flour filled polypropylene composites: Interfacial adhesion and micromechanical deformations. Polymer Engineering and Science, 47, 1246-1255 (2007). https://doi.org/10.1002/pen.20768

[55] Chivrac F., Pollet E., Avérous L.: Progress in nano-biocomposites based on polysaccharides and nanoclays. Materials Science and Engineering R: Reports, 67, 1-17 (2009).

https://doi.org/10.1016/j.mser.2009.09.002 